to safety, nanomaterials, environmental, and multidisciplinary risk management applications. Banding strategies and processes were developed to provide a standardised and simplified framework to identify and reduce occupational risk factors for emergency preparedness and response personnel.

Result The U.S. NIOSH Occupational Exposure Banding process is now available to assist in protecting emergency response personnel from hazardous material exposures for tens of thousands of chemicals lacking Occupational Exposure Limits. Banding strategy frameworks for emergency preparedness have also been applied to physical and biological exposures. This framework provides consistency for informed risk management decisions that assists in identifying emergency-related occupations and provides proven risk communication for the development of trainings and interventions.

Discussion Emergency response scenarios include exposure potential for both noncommunicable and communicable workrelated diseases. Therefore, medical and support personnel must be considered in multiple emergency preparedness parameters. The International Occupational Hygiene Association (IOHA) is seeking collaborations to develop and communicate trainings that increase awareness of these occupational risk factors and provide intervention techniques to increase response capacities and minimise public health consequences for emergency preparedness, surveillance, and response.

\section{ARE WORK FACTORS ASSOCIATED WITH RETURN-TO- WORK IN AN OUT-OF-HOSPITAL CARDIAC ARREST SURVIVORS COHORT?}

\footnotetext{
${ }^{1,2}$ Alexis Descatha*, ${ }^{3}$ Florence Dumas, ${ }^{4}$ Wulfran Bougoin, ${ }^{4}$ Alain Cariou, ${ }^{4}$ Guillaume Geri. ${ }^{1}$ AP-HP, EMS (Samu92), Occupational Health Unit, University hospital of Poincare Garches, France; ${ }^{2}$ Univ Versailles St-Quentin, Versailles, France; Inserm, UMS 011 UMR1168, Villejuif, France; ${ }^{3}$ Paris Descartes University, AP-HP, INSERM U970, Emergency Department, Cochin hospital, France; ${ }^{4} A P-H P$, Paris Descartes University, Medical Intensive Care unit, Cochin Hospital, INSERM U970
}

\subsection{6/oemed-2018-ICOHabstracts.335}

Introduction Although survival rates after out-of-hospital cardiac arrest (OHCA) have improved, little is known about return-to-work of OHCA survivors and predictors. This study aims to study return-to-work in survivors OHCA.

Methods All consecutive OHCA survivors of our intensive care unit between 2000 and 2013 aged 18-65 years, and who had been working up to the OHCA had been included. Available data for pre-hospital care, in-hospital care, and care after hospital discharge, such as work items (work location, job classification, nature of the job) have been compared with work status and return-to-work.

Result Among 379 survivors followed, 153 were included in the study, and 96 returned to work (62.8\%), mostly at the same job ( $n=72,75 \%$ of 96). Predictors of return to work were younger age (adjusted odds ratio ORa 3.64 [1.10; 12.02], positions as managers and professionals, and services and sales workers (compared to technicians and associate professionals, clerical support workers, respectively ORa 3.43 $[1.05 ; 11.22]$ and $4.69[1.14 ; 19.37])$, workplace occurrence (ORa 11.72 [1.37; 99.93]). Workplace location was strongly associated with low flow, but not with no flow nor with? other characteristic of the chainof survival.

Discussion The study emphasised the importance of return-towork after OHCA and anticipation related to work location. On behalf of all the co-author, I agree our abstract will be being published by the BMJ OEM under the licence 'Licence to BMJ Publishing Group Ltd ('BMJ') for publication of conference abstracts'.

\section{POSITION STATEMENT OF THE ICOH WORKING GROUP ON 'EMERGENCY PREPAREDNESS AND RESPONSE IN OCCUPATIONAL HEALTH (EPROH)'}

\begin{abstract}
${ }^{1,2}$ Alexis Descatha*, ${ }^{3,4}$ Susanne Schunder-Tatzber, ${ }^{5}$ Jefferey Burgess, ${ }^{6}$ Pascal Cassan, ${ }^{7}$ Tatsuhiko Kubo, ${ }^{8}$ Sylvie Rotthier, ${ }^{9}$ Koji Wada, EPROH scientific committee*, ${ }^{1}$ Michel Baer. ${ }^{1}$ AP-HP, EMS (Samu92), Occupational Health Unit, University hospital of Poincare site, Garches, France; '2Univ Versailles St-Quentin, Versailles, France; Inserm, UMS 011 UMR1168, F-, Villejuif, France; ${ }^{3}$ OMV AG, Corporate Health Management, A-1020 Vienna, Trabrennstr.4-6; Austria; ${ }^{4}$ Austrian Academy for Occupational Health and Prevention, Klosterneuburg, Austria; ${ }^{5}$ University of Arizona Mel and Enid Zuckerman College of Public Health, Tucson, Arizona, USA; ${ }^{6}$ Global First Aid Centre of the International Federation of Red Cross-Crescent Societies, Paris, France; ' Department of Public Health, University of Occupational and Environmental Health Kitakyushu Japan; ${ }^{8}$ La Poste Service Medical/ Groupement Infirmier du Travail (GIT), Paris, France; ${ }^{9}$ Bureau of International Health Cooperation NCGM, Tokyo, Japan
\end{abstract}

\subsection{6/oemed-2018-ICOHabstracts.336}

Introduction The Emergency Preparedness and Response in Occupational Health (EPROH) scientific committee was developed to raise awareness of emergency risks for workers, to train managers, employees, and medical staff to prepare for and prevent accidents, acute medical events and disasters, and to mitigate their impact. The committee proposes a position statement on the fundamental need for prevention, response, first-aid treatment, and care in the field of occupational health care.

Methods This position statement was developed following Evidence Based Medicine principles, including literature review, practice networking, and surveys including workers' expectations.

Result The scope of the EPROH group will be focused on Emergency Plans, Procedures, Preparedness, and Training. To ameliorate the dramatic situation of workplace fatalities and accidents/events, EPROH experts have developed recommendations for what every worker should expect in case of a medical emergency, work-related or not, minor or major, while working for his/her company. Minimum response plans for every workplace include information about initial management and contact information. First aid must be encouraged, and occupational health and safety professionals will have to develop procedures that detail responses to emergencies, from minor events to major disasters. As needed, emergency providers should be followed up regularly by an occupational specialist for extended intervals after an event.

Discussion Although global harmonisation, local adaptation, and additional research are needed, this position statement emphasises the importance of having a global statement on the multiple aspects of emergency preparedness and response in occupational settings for every worker everywhere in the world. 